\title{
Lapine T-Lymphocyte Immune Globulin
}

National Cancer Institute

\section{Source}

National Cancer Institute. Lapine T-Lymphocyte Immune Globulin. NCI Thesaurus. Code C80833.

A preparation of purified, pasteurized, gamma globulin obtained by the immunization of rabbits with human thymocytes, with T-cell depleting and immunosuppressive activities. Upon administration, rabbit anti-thymocyte globulin (rATG) specifically recognizes, modulates and destroys T-lymphocytes. Although the exact mechanism of action by which rAT G causes immunosuppression is not completely understood, it is likely caused by a combination of T-lymphocyte depletion and reduction in T-cell activation and their cytotoxic activities. Administering ATG with chemotherapy prior to stem cell transplantation may reduce the risk of graft-versus-host disease (GvHD). 